\section{US, Soviets resume space collaboration \\ Washington}

AFTER a lapse of five years, the United States and the Soviet Union will soon officially join forces on a number of space and astronomy projects, including the exploration of Mars. On 15 April, in Moscow, Secretary of State George Shultz and Foreign Minister Edvard Shevardnadze put their names to a wideranging treaty specifying 16 areas in which joint efforts are proposed. The previous US-Soviet collaboration, of which the Apollo-Soyuz mission was the centrepiece, was cancelled in 1982 after the imposition of martial law in Poland.

The treaty was negotiated in October last year, but the signing had been delayed until a sufficiently high-level meeting. In the meantime, interagency bargaining in the US reduced a longer list of collaborative projects down to the sixteen now agreed upon. Certain topics involving advanced technology were omitted, and for the projects that remain, there will be no action until a review process ensures that nothing "unwarranted" is revealed to the opposite side.

Both sides are looking forward to a resumption of some plans and a beginning to others. Peter Smith, of the Division of International Affairs at the $\mathrm{Na}$ tional Aeronautics and Space Administration (NASA), says that scientists will be trying to "pick up the pieces" after a five-year halt.

The new agreement covers a lot of ground. In space exploration, both Mars and Venus are immediate targets. The Mars Observer programme for remote sensing of the Martian surface will be joined with a Soviet plan to land an unmanned vehicle on Phobos, the larger of Mars's two moons, and the US Deep Space Network will be used to track the lander's movements. For Venus, radar data from the Venera 15 and 16 probes will help the United States to plan their Magellan mission, data from which will then be shared.

Informal contacts between individual scientists have proceeded, with ups and downs, in the absence of official sanction, but the new treaty, according to Smith, will make possible co-ordinated efforts in large, long-term projects.

A particularly exciting prospect for astronomers involves the Soviet plan to put a radiotelescope into orbit. Linked with other radiotelescopes around the world, it would make possible interferometry with a baseline of enormous length, allowing the structure of quasars, for instance, to be resolved in fine detail.

David Lindley

\title{
Stanford Linear Collider set for highest energies
}

\section{Palo Alto, California}

THE Stanford Linear Accelerator Center last week proudly showed off the new Stanford Linear Collider (SLC), expected by summer to produce the world's most powerful electron-positron collisions

To achieve SLC's collision energies of $100 \mathrm{GeV}$, Stanford spent $\$ 115$ million improving the 21-year old Stanford Lin-

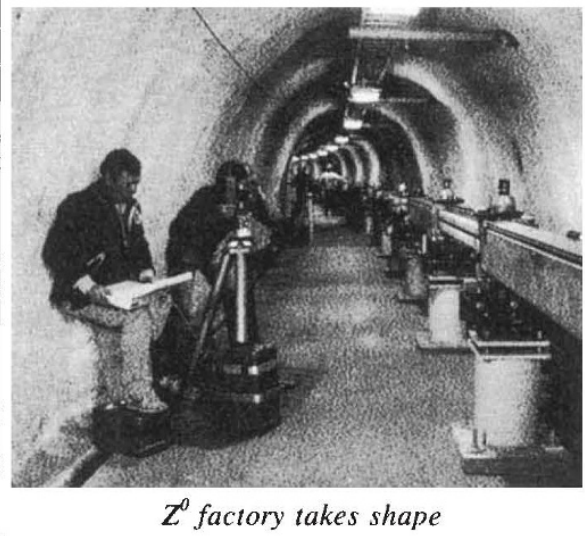

ear Accelerator. Two hundred of the 244 original XK5 klystrons, designed to accelerate electrons and positrons to 20 $\mathrm{GeV}$, have been replaced by the more powerful 5045 klystrons. After bunching to improve luminosity and damping to reduce transverse emittance, positrons and electrons are injected into the twomile-long main accelerator. When the electron and positron bunches reach 50 $\mathrm{GeV}$ they are sent down two arcs, bringing them to the collision area in the large detector hall.

Construction of SLC was completed last month, and the system is now being tuned for studying the $Z^{0}$, one of the

particles essential to the WeinbergSalam theory of electroweak unification. The chief advantage of linear accelerators over their circular counterparts is that they do not suffer energy losses from synchrotron radiation, a consequence of beam bending. The disadvantage of the linear machines, however, is that the beam must be focused to achieve a sufficiently high luminosity. In a storage ring a bunch of accelerated particles is reused until the particle density has been reduced by many collisions, but a linac's colliding beams are 'thrown away' once they have passed through the interaction area. If particles with a given luminosity in a storage ring lose one per cent of their energy per circuit, a linear collider of equivalent energy efficiency must have a beam with 100 times the luminosity.

When tuning is completed in a few weeks, the positron and electron beams at the collision point will be in bunches $1.5 \mathrm{~mm}$ and 3 microns in diameter, each containing 70,000 million particles. With a repetition rate of 60 cycles per second, the scientists at SLC hope to create about $10 \mathrm{Z}^{0}$ particles per day during the first year of operation. Later they want to increase the daily production rate to $300 \mathrm{Z}^{0}$ particles.

Now that SLC construction is completed, the team at Stanford, under Nobel laureate Burton Richter, has begun to think about the next generation of linear colliders. They envision a pair of linacs, each about $5.5 \mathrm{~km}$ long, pointing at each other. They would be able to produce electrons and positrons at collision energies between 300 and $2,000 \mathrm{GeV}$.

Peggy Hellweg

\section{UK industrial support slows}

London

DESPITE repeated appeals from the government that British universities should look increasingly to the private sector for funds, the latest figures show that the rate of increase of income from industry and commerce halved last year. Provisional figures released last week by the University Grants Committee show that although university income from industry and commerce increased in 1985-86 by more than $£ 11$ million (or 24 per cent) to $£ 59$ million, the rate of increase is less than the 46 per cent scored in the previous year. As a proportion of the total income for specific research projects, the contribution from industry increased by only 0.5 per cent.

Many universities have set up special arrangements for attracting industrial in- vestment. But the funds the sponsors offer frequently fail to account sufficiently for the indirect costs of research. "Many vice-chancellors believe that universities cannot afford to accept too many contract grants from industry because of the overheads", the committee spokesman said.

Last week's provisional figures show increases in other sources of non-government funds, with a 26 per cent increase in the contributions of private charities to $£ 72.2$ million.

Overseas sponsors, including companies and foreign governments, spent $\mathbf{2 8 . 5}$ million, an increase of a third on the previous year. Earnings from short courses, many of them specifically for industry, increased by a half to $£ 39$ million.
Simon Hadlington 